\title{
Ageing Of The Workforce: Effects On The Labour Market With Participation And Retirement
}

\author{
Ram SriRamaratnam, Julian Williams and Xintao \\ Zhao \\ Ministry of Business, Innovation \& Employment \\ Wellington
}

\begin{abstract}
Ageing of the work force in New Zealand is an important determinant of labour market dynamics. In addition to the median age and the proportion of workers in retirement age, the nature of occupations and health and financial security are also important determinants of participation and retirement.
\end{abstract}

The baby boom generation has approached their retirement years and the age structure of the working age population has also significantly altered. Consequently, the retirement of older workers is expected to make-up an important source of new job openings over the coming decades.

Estimating and forecasting likely future retirement rates by occupational groups is of considerable interest, and provides further insights into labour market dynamics.

In this study, recent historical retirement rates for broad (3-digit) ANZSCO occupational groups were derived using an internationally accepted methodology known as the cohort component method, adapted to allow for some participation by older age groups. Occupational employment data by age extracted from the recently released 2013 Census was analysed along with the corresponding data from the 2006 Census to estimate the average retirement rates over the 2006-13 period. These rates are then used to project future retirement rates over the 2013-20 period for the same broad occupational groups. Projections were based on the Working Age Population projections for age groups and their associated participation rates.

\section{Introduction}

Motivation:

Structural ageing (increasing longevity and falling birth rates) along with the ageing cohort of the post WWII baby boomers (Alpass and Mortimer, 2007) are key factors underlying demographic changes in advanced industrialised nations. This demographic effect of ageing has an important impact on the labour market.

The New Zealand workforce may not be one of the oldest amongst the Western Economies, but the need to replace the present workforce due to retirement is large enough not to be overlooked.

Recently, with strong employment growth and additional opportunities for those close to the retirement age, the rate of employment growth is about two times the employment growth required to replace retiring workers. 
Key Considerations:

Labour supply is made up of the working age population (WAP) and the level of labour force participation rate (LFPR) of workers of different age groups.

In this paper, the estimated and projected WAP of different age groups and the age distribution of those who are employed in different occupational groups are used to estimate retirement rates for the recent historical (2006-13) period and to project these rates for the 2013-20 period.

\section{Methods}

The results reported in this paper assessing the level of ageing of the workforce by occupational groups and the estimation and projections of the retirement rates are based on customised data extracted from the 2006 and 2013 Census.

Other data sources include Household Labour Force Survey (HLFS) Unit Record data and labour force projections by Statistics New Zealand which enabled the estimates of LFPR for historical periods and forecasts.

The estimated and projected retirement rates were computed using the Cohort- Component method (CEET, Monash University, Australia, 2003) previously employed to estimate and project the retirement rates for the 2001-06 and 2006-11 periods, respectively.

\section{Key factors influencing retirement and participation}

A number of generic drivers and specific factors determine the extent of participation by workers in different occupational groups and their decision to retire from paid work. These include demographic and economic factors, policy settings, occupational characteristics and personal circumstances.

Levels of participation and retirement between Census years are influenced by the age profile of the different occupations covering the labour market and inter-census inflows and outflows.

Generic factors influencing participation include general economic factors and Government policy towards participation of older workers after their eligibility for superannuation benefits at 65 years. Compulsory retirement ceased in 1999 and surcharges on extra income earned while receiving superannuation were also removed.

Occupation type is an important specific feature influencing participation. This is due to nature of the occupations themselves in terms of the level of physical and/or cognitive effort involved in performing the duties and the gender mix typically prevalent.

Other specific features include personal circumstances of the individuals with respect to their financial need and the ability to work based on family and health considerations.

\section{Measures of ageing and retirement:}

\section{Possible links}

Useful measures of ageing and the age profile of occupational groups are summary measures (of central tendency) such as the median age and/or the proportion of those in the retirement age (type of the age distribution focusing on the right tail). The levels and changes in these measures provide insights about the extent and the pace of ageing. 
Retirement rates computed using the cohort-component method for occupational groups are summarised for broad skill groups in this paper. They are also summarised for selected occupation groups to illustrate behaviour for different sectors and industries.

In this paper, measures of retirement are:

- Retirement Rates for Occupational groups

- Retirement Rates summarised for Skill groups

- Investigated for groups of Occupations in different sectors/industries

In this paper, the measures of ageing and the measures of retirement are compared for selected occupation groups to assess the likely links between age and retirement by occupation. This highlights links which are strong and transparent in the case of some occupational groups. In other cases links are unobserved due to unmeasured factors including the characteristics of occupational groups and personal circumstances of individuals determining their participation.

These factors are important determinants of the duration of participation by older workers in different segments of the labour market. They impact on retirement rates within specific occupational groups and labour supply across the New Zealand labour market.

\section{Median age of the Working Age Population (WAP) \\ Table 1: WAP \& Median age over time}

\begin{tabular}{|l|l|l|}
\hline Census & $\begin{array}{l}\text { Total } \\
\text { WAP }\end{array}$ & $\begin{array}{l}\text { Median } \\
\text { Age }\end{array}$ \\
\hline $\mathbf{2 0 0 1}$ & $2,889,534$ & 41 \\
$\mathbf{2 0 0 6}$ & $3,160,371$ & 43 \\
$\mathbf{2 0 1 3}$ & $3,376,416$ & 45 \\
\hline
\end{tabular}

\begin{tabular}{|l|ll|}
\cline { 1 - 1 } Changes: & & \\
\hline 2001-06 & 270,837 & 2 \\
2006-13 & 216,045 & 2 \\
\hline
\end{tabular}

Source: Population Census, Statistics New Zealand

Total WAP rose by about $216 \mathrm{~K}$ over the 7 year inter-census period (2006-13) or on average $30 \mathrm{~K}$ per year. This followed a $271 \mathrm{~K}$ increase $(54 \mathrm{~K}$ per year) over the previous 5 year inter-census period (2001-06).

The Median Age of the WAP rose from 43 to 45 during the recent slightly longer ( 7 year) intercensus period of 2006-13, which was similar to the rate of change (41 to 43) during the previous shorter (5 year) inter-census period.

This illustrates the significant slowing of the rate of growth in the WAP by almost half (from about $54 \mathrm{~K}$ per year to $30 \mathrm{~K}$ per year) while ageing at a slightly slower rate in terms of the Median Age. 


\section{Ageing of the Working Age population- by Broad Age Groups}

Retirement age group - estimated \& projected

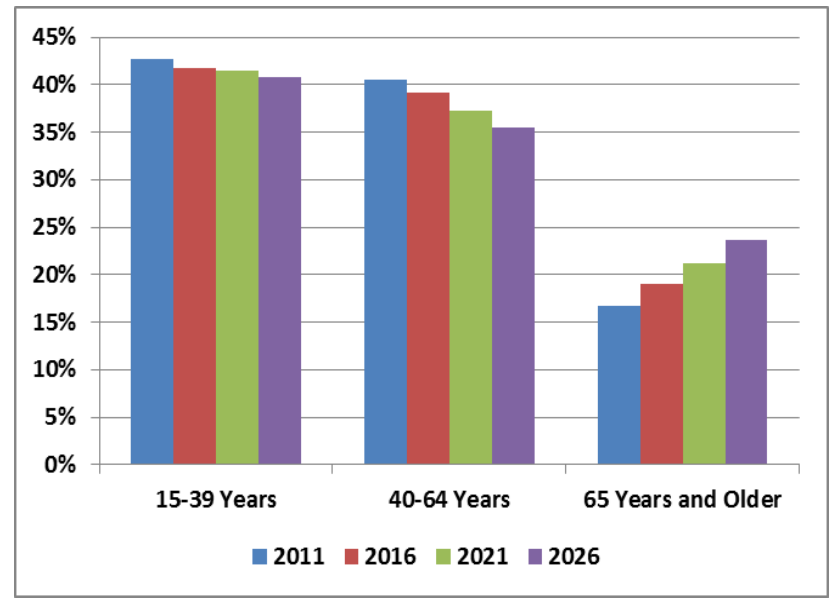

Source: Statistics New Zealand Projections, 2012 (2011 base)

The WAP which is made up of those who are 15 years old and over is projected to become older over the next 10-15 years compared to 2011. Those who are in the older age group (65 years and over), estimated to be 17 per cent in 2011 is projected to rise to 24 per cent by 2026 . During the same period, those in the next older age group (40-64 years) are expected to decline from 41 per cent to 36 per cent while those in the younger age group (15-39 years) are projected to decline only slightly by about 2 per cent.

\section{Participation Rates by Broad Age Groups}

Table 2: Participation rates by broad age groups

\begin{tabular}{|r|rrr|}
\cline { 2 - 4 } \multicolumn{1}{c|}{} & \multicolumn{3}{|c|}{ Broad Age Groups } \\
\hline Participation Rates & $\mathbf{1 5 - 3 9}$ & $\mathbf{4 0 - 6 4}$ & $\mathbf{6 5 +}$ \\
\hline $\mathbf{2 0 1 1}$ & 0.73 & 0.83 & 0.19 \\
$\mathbf{2 0 1 6}$ & 0.74 & 0.84 & 0.25 \\
$\mathbf{2 0 2 1}$ & 0.75 & 0.85 & 0.28 \\
$\mathbf{2 0 2 6}$ & 0.75 & 0.86 & 0.31 \\
\hline
\end{tabular}

Source: From Population and Labour Force projections, Statistics New Zealand

Participation rates (derived from the WAP and Labour Force projections) by broad (25 year) age groups show different patterns of change for the 2011-26 period.

The average participation rates for the younger (15-39) and the next (40-64) age group show very modest increases of 2 and 3 per cent, respectively. The average participation rate for the retirement age group (65+) shows significant change from 19 per cent in 2011 to over 30 per cent by 2026. 
Age distribution of Employed - in Census years (2001, 2006 and 2013) and 2020

Employment by age groups - Census \& Projected

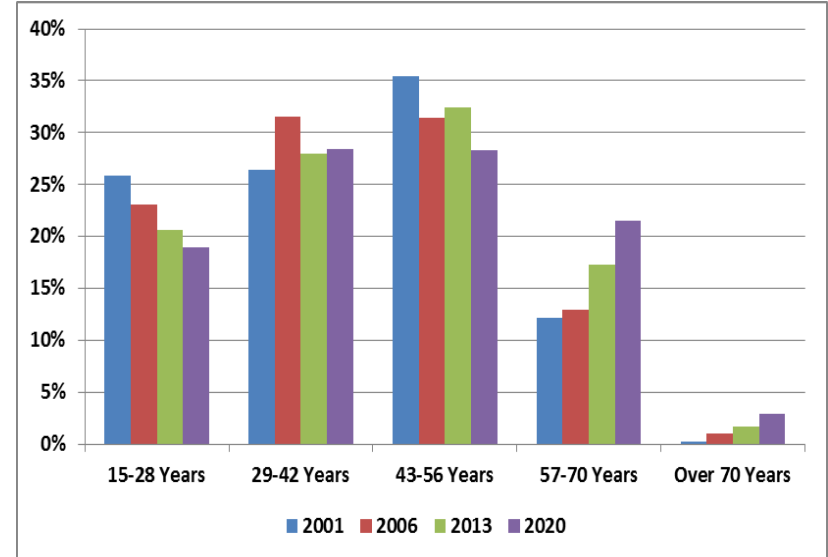

Source: Population Census (2001, 2006 \& 2013) and Projections

for 2020, Statistics New Zealand

The age distribution of those employed, as a proportion of the WAP is calculated for five age groups. The key finding is that there was a steady decline of those in the 15-28 age group and a steady rise in the 57-70 age group during the past three census years (2001, 2006 and 2013). This is projected to continue to 2020 .

\section{Proportion of Older Workers Employed}

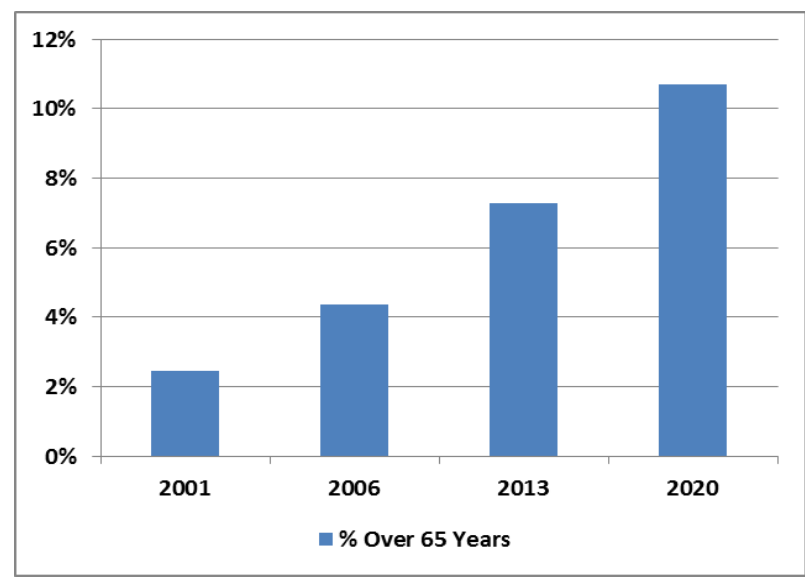

The age groups in between indicate a general rise for the 29-42 age group and a general decline for the 43-56 age group. The proportion of the older workers employed who are in the retirement age group (over 65 years) was about 2 per cent in 2001 and rose to 7 per cent by 2013. This is projected to reach11 per cent by 2020 .

In the UK, workers who are aged 65 years and over doubled over the 10 year period to 2011(Post Note, 2011). This has led to the retirement age steadily rising over this period to 64.5 years for men and 62.0 years for women in 2011. It is reported that the average retirement age that retirees reported in the US have risen to 62 years. Non-retired Americans expect to retire at age 66 (Riffkin, Gallup, 2014).

\section{Ageing of the Employed by Skill Groups: Median Age}

Ageing of the workforce by skill group can be assessed using the levels \& changes in the median age of employed across broad skill groups covering 'Highly skilled', 'Skilled', 'Semi-skilled' and 'Elementary skilled'.

\begin{tabular}{|l|l|l|}
\hline Skill Group & ANZSCO* & Description \\
\hline Highly Skilled & 100,200 & Managers, Professionals \\
\hline
\end{tabular}




\begin{tabular}{|l|l|l|}
\hline Skilled & 300 & Technicians/Trades Workers \\
\hline Semi-Skilled & $400,500,600$ & Service/Sales/Support Workers \\
\hline Elem-Skilled & 700,800 & Machine Operators, \& Labour \\
\hline
\end{tabular}

The highly skilled group includes managers (100) and professional (200 level) ANZSCO occupations. The skilled group includes technicians and trades workers (300), the semi-skilled group (400-600) the sales, service and office workers while the elementary skilled group include the machinery operators, drivers and labour (700-800).

Table 3: Median Age levels \& Changes by Skill

\begin{tabular}{|c|c|c|c|}
\hline & \multicolumn{2}{|c|}{ Median Age } & Change \\
\hline Census & 2006 & 2013 & $2006-2013$ \\
\hline Highly Skilled & 41.7 & 43.7 & 2.00 \\
\hline Skilled & 38.6 & 41.7 & 3.05 \\
\hline Semi-Skilled & 38.3 & 41.2 & 2.88 \\
\hline Elem Skilled & 39.1 & 42.2 & 3.13 \\
\hline Average & 39.4 & 42.2 & 2.76 \\
\hline Total WAP & 43.0 & 45.0 & 2.0 \\
\hline
\end{tabular}

It was noted before that the median age of the total WAP increased by 2 from 43 to 45 between 2006 and 2013. The 'average' median age of the employed across these four skill groups rose by 2.76 from about 39 to 42 over this 7 year period, nearly one year more than for WAP.

The median age is highest for the highly skilled group in 2006 and also in 2013 but indicate the slowest increase. The median age is lower than or equal to the overall average for the other 3 skill groups. The increase in the median age during the 2006 and 2013 period is higher than 3 for the skilled and elementary skilled groups and greater than the increase in the overall average (2.76).

The different levels of the median age for the four skill groups reflect the nature of the occupations included in these groups and the types of roles performed and the level of experience required for them. The rates of change in the median age, on the other hand, indicate the level of inflows and outflows into the occupations making up these skill groups during the 2006 to 2013 period.

\section{Ageing of the Employed by Skill Groups:}

\section{Workers in Retirement Age}

While there is no age of compulsory retirement in New Zealand, the age of eligibility of national superannuation is 65 years. It is therefore useful to assess the percent of workers who are 65 years and older.

Largest percent of older workers were in Elementary occupations followed by the Highly skilled occupations in 2006 and 2013 and the overall share has risen by 3 per cent during this period. The projected shares suggest that the overall share will rise faster between 2013 and 2020 as Skilled and Semi-Skilled occupations will rise faster. 


\begin{tabular}{|l|ll|l|}
\hline Employed & 2006 & 2013 & 2020 \\
\hline Highly Skilled & $4.2 \%$ & $7.0 \%$ & $9.9 \%$ \\
Skilled & $3.6 \%$ & $6.2 \%$ & $11.4 \%$ \\
Semi-Skilled & $3.6 \%$ & $6.8 \%$ & $11.9 \%$ \\
Elem Skilled & $5.0 \%$ & $8.3 \%$ & $12.9 \%$ \\
\hline
\end{tabular}

The latter group includes drivers working in public transport who in fact have the highest proportion (26 per cent) in this age group in 2013 with also the highest rise of 9 per cent between 2006 and 2013. Closely behind the Public sector drivers are Farmers and Farm Managers, Real Estate Agents and Miscellaneous Education Professionals with the next highest older workers (15-16 per cent) in 2013.

Public sector drivers (56) and Real Estate Agents (52) also had the highest median age in 2013 rising by 3 years between the 2006 and 2013 census (Table 5). The median age of 18 occupational groups out of 97 in total rose by 4 and 5 years between the 2006 and 2013 census (Table 6), all of them in the 300-800 occupational groups excluding the managers and professionals.

\section{Retirement rates estimated using the Cohort Component Method}

The cohort-component method uses data at two different points in time, to establish the inflows and the outflows for an occupation by age-cohorts. Annual data is typically used, however due to the lack of availability of this type of data for New Zealand, five yearly Census data was used.

Shah and Burke (p. 652, 2001) describe the net flow from an occupation as being the change in size of cohort over a certain period and given by:

Fat $=E a+1 t+1$-Eat., where Fat is the net flow from age cohort a at time $t$

The authors go on to outline that if the size of the cohort decreased (Fat $<0$ ), then there has been an outflow (-Fat), otherwise the net outflow is equal to zero. This is true if the employment in an occupation is expanding, however if employment is decreasing then the net outflow is equal to sum of outflows minus the size of the contraction.

\section{Retirement Rates (RRs) by Broad Skill Groups}

Table 7: Retirement rates by skill over time

\begin{tabular}{|l|l|l|}
\cline { 2 - 3 } \multicolumn{1}{c|}{} & \multicolumn{2}{|c|}{ Retirement rates } \\
\hline Employed & $\mathbf{2 0 0 6 - 1 3}$ & $\mathbf{2 0 1 3 - 2 0}$ \\
\hline Highly Skilled & $1.17 \%$ & $1.20 \%$ \\
Skilled & $1.24 \%$ & $1.45 \%$ \\
Semi-Skilled & $1.10 \%$ & $1.23 \%$ \\
Elem Skilled & $1.22 \%$ & $1.31 \%$ \\
\hline Average & $\mathbf{1 . 1 8 \%}$ & $\mathbf{1 . 3 0} \%$ \\
\hline
\end{tabular}

Historical Retirement Rates estimated using the 2013 and 2006 Census data for 3-digit ANZSCO Occupational groups were summarised for the four broad skill groups in order to compare changes in these rates over time. 
Average RRs across the four skill groups are estimated to rise slightly from about $1.2 \%$ (2006-13) to $1.3 \%(2013-20)$ but the rate of change varies by individual skill. There was little change amongst the Highly skilled group (0.03\%) in the 2006 to 2013 period and the greatest change amongst the Skilled group (0.21\%). The change for the other two lower skill groups was in the range of $0.13 \%$ (Semi-skilled) and $0.09 \%$ (Elementary skilled). 


\begin{tabular}{|c|c|c|c|c|}
\hline \multirow[b]{3}{*}{1} & \multirow[b]{2}{*}{ ANZCO Occupation - Ranked by $2013 \% 65$ years and over } & \multicolumn{2}{|c|}{$\% 65$ years and over } & \multirow[b]{2}{*}{ Changes } \\
\hline & & 2006 & 2013 & \\
\hline & 731 Automobile, Bus and Rail Drivers & $17 \%$ & $26 \%$ & $9 \%$ \\
\hline 2 & 121 Farmers and Farm Managers & $12 \%$ & $16 \%$ & $4 \%$ \\
\hline 3 & 612 Real Estate Sales Agents & $8 \%$ & $16 \%$ & $7 \%$ \\
\hline 4 & 249 Miscellaneous Education Professionals & $11 \%$ & $15 \%$ & $4 \%$ \\
\hline 5 & 561 Clerical and Office Support Workers & $7 \%$ & $13 \%$ & $5 \%$ \\
\hline 6 & 362 Horticultural Trades Workers & $8 \%$ & $13 \%$ & $5 \%$ \\
\hline 7 & 242 Tertiary Education Teachers & $6 \%$ & $12 \%$ & $6 \%$ \\
\hline 8 & 393 Textile, Clothing and Footwear Trades Workers & $7 \%$ & $12 \%$ & $5 \%$ \\
\hline 9 & 141 Accommodation and Hospitality Managers & $7 \%$ & $11 \%$ & $5 \%$ \\
\hline 10 & 841 Farm, Forestry and Garden Workers & $7 \%$ & $11 \%$ & $4 \%$ \\
\hline 11 & 423 Personal Carers and Assistants & $6 \%$ & $11 \%$ & $4 \%$ \\
\hline 12 & 111 Chief Executives, General Managers and Legislators & $7 \%$ & $11 \%$ & $4 \%$ \\
\hline 13 & 521 Personal Assistants and Secretaries & $6 \%$ & $11 \%$ & $5 \%$ \\
\hline 14 & 732 Delivery Drivers & $6 \%$ & $10 \%$ & $5 \%$ \\
\hline 15 & 811 Cleaners and Laundry Workers & $6 \%$ & $10 \%$ & $4 \%$ \\
\hline 16 & 532 Keyboard Operators & $5 \%$ & $10 \%$ & $6 \%$ \\
\hline 17 & 211 Arts Professionals & $8 \%$ & $10 \%$ & $2 \%$ \\
\hline 18 & 272 Social and Welfare Professionals & $6 \%$ & $10 \%$ & $4 \%$ \\
\hline 19 & 394 Wood Trades Workers & $5 \%$ & $9 \%$ & $4 \%$ \\
\hline 20 & 212 Media Professionals & $6 \%$ & $9 \%$ & $4 \%$ \\
\hline 21 & 271 Legal Professionals & $5 \%$ & $9 \%$ & $4 \%$ \\
\hline 22 & 899 Miscellaneous Labourers & $6 \%$ & $9 \%$ & $3 \%$ \\
\hline 23 & 531 General Clerks & $4 \%$ & $9 \%$ & $4 \%$ \\
\hline 24 & 542 Receptionists & $4 \%$ & $9 \%$ & $5 \%$ \\
\hline 25 & 551 Accounting Clerks and Bookkeepers & $4 \%$ & $8 \%$ & $4 \%$ \\
\hline 26 & 323 Mechanical Engineering Trades Workers & $5 \%$ & $8 \%$ & $3 \%$ \\
\hline 27 & 733 Truck Drivers & $4 \%$ & $8 \%$ & $4 \%$ \\
\hline 28 & 312 Building and Engineering Technicians & $4 \%$ & $8 \%$ & $4 \%$ \\
\hline 29 & 721 Mobile Plant Operators & $4 \%$ & $8 \%$ & $3 \%$ \\
\hline 30 & 231 Air and Marine Transport Professionals & $4 \%$ & $8 \%$ & $4 \%$ \\
\hline 31 & 821 Construction and Mining Labourers & $5 \%$ & $8 \%$ & $3 \%$ \\
\hline 32 & 222 Financial Brokers and Dealers, and Investment Advisers & $5 \%$ & $8 \%$ & $3 \%$ \\
\hline
\end{tabular}


Table 5: Ageing of the Employed - Occupations with Highest Median Age in 2013

\begin{tabular}{|c|c|c|c|c|}
\hline & ANZCO Occupation - Median Age Ranked in 2013 & 2006 & 2013 & Changes \\
\hline 1 & 731 Automobile, Bus and Rail Drivers & 53 & 56 & 3.0 \\
\hline 2 & 612 Real Estate Sales Agents & 49 & 52 & 3.0 \\
\hline 3 & 111 Chief Executives, General Managers and Legislators & 47 & 49 & 2.0 \\
\hline 4 & 134 Education, Health and Welfare Services Managers & 48 & 49 & 1.0 \\
\hline 5 & 242 Tertiary Education Teachers & 47 & 49 & 2.0 \\
\hline 6 & 393 Textile, Clothing and Footwear Trades Workers & 44 & 49 & 5.0 \\
\hline 7 & 423 Personal Carers and Assistants & 47 & 49 & 2.0 \\
\hline 8 & 121 Farmers and Farm Managers & 46 & 48 & 2.0 \\
\hline 9 & 521 Personal Assistants and Secretaries & 45 & 48 & 3.0 \\
\hline 10 & 141 Accommodation and Hospitality Managers & 45 & 47 & 2.0 \\
\hline 11 & 249 Miscellaneous Education Professionals & 46 & 47 & 1.0 \\
\hline 12 & 254 Midwifery and Nursing Professionals & 45 & 47 & 2.0 \\
\hline 13 & 272 Social and Welfare Professionals & 45 & 47 & 2.0 \\
\hline 14 & 362 Horticultural Trades Workers & 43 & 47 & 4.0 \\
\hline 15 & 411 Health and Welfare Support Workers & 45 & 47 & 2.0 \\
\hline 16 & 512 Office and Practice Managers & 44 & 47 & 3.0 \\
\hline 17 & 561 Clerical and Office Support Workers & 42 & 47 & 5.0 \\
\hline 18 & 733 Truck Drivers & 43 & 47 & 4.0 \\
\hline 19 & 323 Mechanical Engineering Trades Workers & 43 & 46 & 3.0 \\
\hline 20 & 422 Education Aides & 44 & 46 & 2.0 \\
\hline 21 & 442 Prison and Security Officers & 42 & 46 & 4.0 \\
\hline 22 & 532 Keyboard Operators & 41 & 46 & 5.0 \\
\hline 23 & 551 Accounting Clerks and Bookkeepers & 41 & 46 & 5.0 \\
\hline 24 & 811 Cleaners and Laundry Workers & 43 & 46 & 3.0 \\
\hline 25 & 132 Business Administration Managers & 42 & 45 & 3.0 \\
\hline 26 & 231 Air and Marine Transport Professionals & 42 & 45 & 3.0 \\
\hline 27 & 392 Printing Trades Workers & 41 & 45 & 4.0 \\
\hline 28 & 394 Wood Trades Workers & 40 & 45 & 5.0 \\
\hline 29 & 531 General Clerks & 42 & 45 & 3.0 \\
\hline 30 & 711 Machine Operators & 41 & 45 & 4.0 \\
\hline
\end{tabular}

Table 6: Ageing of the Employed-Occupations with Largest Median Age Change (2006-13)

\begin{tabular}{|l|l|l|l|l|l|}
\hline $\mathbf{1}$ & ANZCO Occupation - Median Age Ranked by 2006 to 2013 Change & $\mathbf{2 0 0 6}$ & $\mathbf{2 0 1 3}$ & Changes \\
\cline { 2 - 4 } $\mathbf{2}$ & 324 Panel beaters, and Vehicle Body Builders, Trimmers and Painters & 36 & 41 & 5.0 \\
$\mathbf{3}$ & 393 Textile, Clothing and Footwear Trades Workers & 44 & 49 & \\
$\mathbf{4}$ & 394 Wood Trades Workers & 40 & 45 & 5.0 \\
$\mathbf{5}$ & 532 Keyboard Operators & 41 & 46 & 5.0 \\
$\mathbf{6}$ & 561 Clerical and Office Support Workers & 41 & 46 & 5.0 \\
$\mathbf{7}$ & 839 Miscellaneous Factory Process Workers & 42 & 47 & 5.0 \\
$\mathbf{8}$ & 362 Horticultural Trades Workers & 38 & 43 & 5.0 \\
$\mathbf{9}$ & 391 Hairdressers & 43 & 47 & 5.0 \\
$\mathbf{1 0}$ & 392 Printing Trades Workers & 33 & 37 & 4.0 \\
$\mathbf{1 1}$ & 441 Defence Force Members, Fire Fighters and Police & 41 & 45 & 4.0 \\
$\mathbf{1 2}$ & 442 Prison and Security Officers & 36 & 40 & 4.0 \\
$\mathbf{1 3}$ & 451 Personal Service and Travel Workers & 42 & 46 & 4.0 \\
$\mathbf{1 4}$ & 639 Miscellaneous Sales Support Workers & 36 & 40 & 4.0 \\
$\mathbf{1 5}$ & 711 Machine Operators & 36 & 40 & 4.0 \\
$\mathbf{1 6}$ & 732 Delivery Drivers & 41 & 45 & 4.0 \\
$\mathbf{1 7}$ & 733 Truck Drivers & 39 & 43 & 4.0 \\
$\mathbf{1 8}$ & 899 Miscellaneous Labourers & 43 & 47 & 4.0 \\
\hline
\end{tabular}




\section{Occupations with Older Age Profile:}

Table 8: Older age occupations retirement

\begin{tabular}{|c|c|c|c|}
\hline I. Occupational Groups of Typically 0lder Age Profile & \multicolumn{2}{|c|}{$\% 65$ Years \& 0ver } & RRs \\
\hline Education related 0ccupational Groups & 2013 & $2006-13$ & $2006-13$ \\
\hline 241 School Teachers & $5.8 \%$ & $2.4 \%$ & $1.4 \%$ \\
\hline 242 Tertiary Education Teachers & $11.5 \%$ & $5.8 \%$ & $2.0 \%$ \\
\hline 249 Miscellaneous Education Professionals & $14.7 \%$ & $4.1 \%$ & $1.8 \%$ \\
\hline Average (Unweighted) & $10.7 \%$ & $4.1 \%$ & $1.7 \%$ \\
\hline & $\% 65$ Years & rs \& Over & RRs \\
\hline Health related 0ccupational Groups & 2013 & 2006-13 & $2006-13$ \\
\hline 251 Health Diagnostic and Promotion Professionals & $5.9 \%$ & $1.1 \%$ & $1.4 \%$ \\
\hline 252 Health Therapy Professionals & $5.7 \%$ & $1.7 \%$ & $0.9 \%$ \\
\hline 253 Medical Practitioners & $6.6 \%$ & $1.8 \%$ & $0.8 \%$ \\
\hline 254 Midwifery and Nursing Professionals & $6.0 \%$ & $2.4 \%$ & $1.4 \%$ \\
\hline Average (Unweighted) & $6.1 \%$ & $1.7 \%$ & $1.1 \%$ \\
\hline
\end{tabular}

The education sector and the health sector are generally considered to include occupations with larger share of older workers. Table 8 does not suggest this to be the case with some notable exceptions. Miscellaneous education professionals $(14.7 \%)$ and Tertiary education professionals $(11.5 \%)$ have a larger share of retirement age workers and also retirement rates close to 2.0, which is much higher than the overall average of 1.2 (Table 7).

The proportion of retirement age workers amongst some key health sector professionals has an average of about $6 \%$ compared to about $11 \%$ amongst key education sector occupations. The increase in this share between 2006 and 2013 was also on average about 4 per cent in education and under 2 per cent for health related professions.

Hence, retirement rates over the 2006-13 period on average are higher amongst the professionals in education (1.7 per cent increase) compared to those in health (1.1 per cent increase).

\section{Occupations with Medium Age Profile:}

\section{Table 9: Medium age occupations retirement}

\begin{tabular}{|c|c|c|c|}
\hline II. Occupational Groups of Typically Medium Age Profile & $\% 65$ Year & rs \& Over & RRs \\
\hline Engineering related Occupational Groups & 2013 & 2006-13 & \begin{tabular}{|l|}
$2006-13$ \\
\end{tabular} \\
\hline 232 Architects, Designers, Planners and Surveyors & $5.0 \%$ & $1.9 \%$ & $0.8 \%$ \\
\hline 233 Engineering Professionals & $7.3 \%$ & $3.1 \%$ & $0.9 \%$ \\
\hline 322 Fabrication Engineering Trades Workers & $4.4 \%$ & $1.4 \%$ & $1.3 \%$ \\
\hline 323 Mechanical Engineering Trades Workers & $8.2 \%$ & $3.3 \%$ & $1.8 \%$ \\
\hline Average (Unweighted) & $6.2 \%$ & $2.4 \%$ & $1.2 \%$ \\
\hline & $\% 65$ Year & rs \& Over & RRs \\
\hline Construction related Occupational Groups & 2013 & $2006-13$ & $2006-13$ \\
\hline 133 Construction, Distribution and Production Managers & $6.1 \%$ & $2.5 \%$ & $1.5 \%$ \\
\hline 331 Bricklayers, Carpenters and Joiners & $6.2 \%$ & $1.7 \%$ & $1.8 \%$ \\
\hline 332 Floor Finishers and Painting Trades Workers & $6.7 \%$ & $2.6 \%$ & $1.4 \%$ \\
\hline 333 Glaziers, Plasterers and Tilers & $2.5 \%$ & $0.9 \%$ & $0.9 \%$ \\
\hline 334 Plumbers & $5.9 \%$ & $1.9 \%$ & $1.2 \%$ \\
\hline 341 Electricians & $5.9 \%$ & $2.4 \%$ & $1.2 \%$ \\
\hline Average (Unweighted) & $5.5 \%$ & $2.0 \%$ & $1.3 \%$ \\
\hline
\end{tabular}

The engineering and construction sectors include occupations with typically medium age profile. They also have on average between 5-6 per cent of the workers in the retirement age and retirement rates of 1.2-1.3 per cent on average, only slightly higher than the overall average.

Amongst the engineering related occupational groups, professionals (architects and engineers) had retirement rates of around 1.0 per cent while the trades workers (in fabrication and mechanical engineering) had much higher rates between 1.3 and 1.8 per cent. This was in spite of those in the retirement age (those 65 years and over) being not too dissimilar at around 6 per cent on average in 2013 and rising by 2 per cent on average from levels in 2006. The nature of the physical and difficult tasks, involved in these Trades occupations for the older workers, appear to be the main factor explaining this difference. 
Within the construction related occupational groups, those in the retirement age on average was slightly smaller (5.5 per cent compared to 6.2 per cent) than those in the engineering related occupations. Amongst the 4 trades occupations within building \& construction with similar share (67 per cent ) of those in the retirement age, retirement rates during 2006-13 ranged from 1.2 per cent (for plumbers and electricians) to 1.9 per cent (for Bricklayers, Carpenters and Joiners). The Glaziers, Plasterers and Tilers had less than 3 per cent in the retirement age and retirement rates of less than 1 per cent during the 2006-13 period.

\section{Occupations with Younger Age Profile:}

\section{Table 10: Young age occupations retirement}

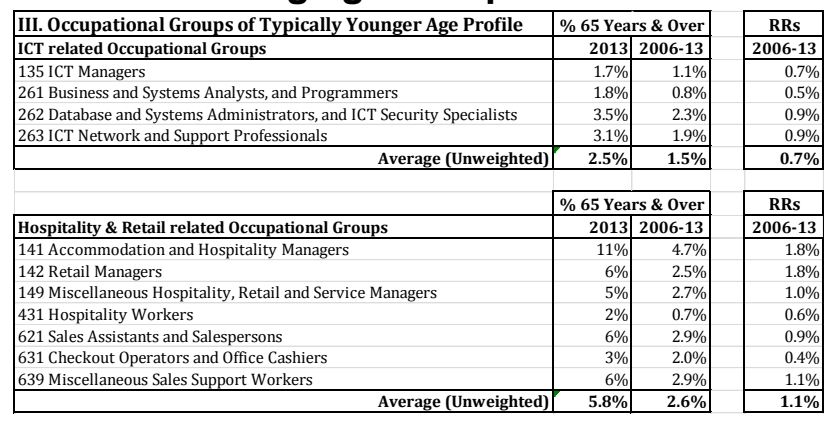

ICT related occupational groups and Hospitality and Retail related sectors include those with much younger workers. Those in the retirement age (65 years and over) are on average very low amongst the ICT occupations (2.5\%) but higher for those in hospitality and retail trade (5.8\%).

The retirement rates for the 2006-13 period was on average very low for the ICT occupational groups

\begin{tabular}{|c|c|c|c|}
\hline & \multirow[b]{2}{*}{ 3-Digit ANZSCO Occ. Groups Ranked by $2006-13$ RRs } & \multicolumn{2}{|c|}{ Avg. Retirement Rates } \\
\hline & & 2006-13 & 2013-20 \\
\hline 1 & 521 Personal Assistants and Secretaries & $2.4 \%$ & $2.6 \%$ \\
\hline 2 & 393 Textile, Clothing and Footwear Trades Workers & $2.3 \%$ & $3.0 \%$ \\
\hline 3 & 612 Real Estate Sales Agents & $2.1 \%$ & $1.5 \%$ \\
\hline 4 & 531 General Clerks & $2.1 \%$ & $2.3 \%$ \\
\hline 5 & 711 Machine Operators & $2.0 \%$ & $2.5 \%$ \\
\hline 6 & 242 Tertiary Education Teachers & $2.0 \%$ & $1.6 \%$ \\
\hline 7 & 392 Printing Trades Workers & $1.9 \%$ & $2.5 \%$ \\
\hline 8 & 121 Farmers and Farm Managers & $1.9 \%$ & $1.7 \%$ \\
\hline 9 & 111 Chief Executives, General Managers and Legislators & $1.8 \%$ & $1.6 \%$ \\
\hline 10 & 141 Accommodation and Hospitality Managers & $1.8 \%$ & $1.2 \%$ \\
\hline 11 & 249 Miscellaneous Education Professionals & $1.8 \%$ & $1.4 \%$ \\
\hline 12 & 331 Bricklayers, Carpenters and Joiners & $1.8 \%$ & $2.1 \%$ \\
\hline 13 & 323 Mechanical Engineering Trades Workers & $1.8 \%$ & $2.1 \%$ \\
\hline 14 & 142 Retail Managers & $1.8 \%$ & $1.7 \%$ \\
\hline 15 & 733 Truck Drivers & $1.7 \%$ & $1.7 \%$ \\
\hline 16 & 394 Wood Trades Workers & $1.7 \%$ & $2.4 \%$ \\
\hline 17 & 532 Keyboard Operators & $1.6 \%$ & $1.9 \%$ \\
\hline 18 & 552 Financial and Insurance Clerks & $1.6 \%$ & $1.7 \%$ \\
\hline 19 & 712 Stationary Plant Operators & $1.6 \%$ & $1.6 \%$ \\
\hline 20 & 731 Automobile, Bus and Rail Drivers & $1.6 \%$ & $1.2 \%$ \\
\hline 21 & 134 Education, Health and Welfare Services Managers & $1.6 \%$ & $1.9 \%$ \\
\hline 22 & 222 Financial Brokers and Dealers, and Investment Advisers & $1.6 \%$ & $1.5 \%$ \\
\hline 23 & 133 Construction, Distribution and Production Managers & $1.5 \%$ & $1.6 \%$ \\
\hline 24 & 832 Packers and Product Assemblers & $1.5 \%$ & $1.8 \%$ \\
\hline 25 & 423 Personal Carers and Assistants & $1.5 \%$ & $1.5 \%$ \\
\hline 26 & 542 Receptionists & $1.5 \%$ & $1.2 \%$ \\
\hline 27 & 831 Food Process Workers & $1.4 \%$ & $1.6 \%$ \\
\hline 28 & 332 Floor Finishers and Painting Trades Workers & $1.4 \%$ & $1.5 \%$ \\
\hline 29 & 251 Health Diagnostic and Promotion Professionals & $1.4 \%$ & $1.5 \%$ \\
\hline 30 & 241 School Teachers & $1.4 \%$ & $1.3 \%$ \\
\hline
\end{tabular}


(0.7 per cent and higher for hospitality and retail trade related occupational groups (1.1 per cent).

Business and systems analysts and programmers amongst ICT workers and hospitality workers and checkout operators and office cashiers in retail trade had some of the lowest retirement rates during the 2006-13 period (0.4-0.6 per cent).

The percentage of older (65+) workers is lower for most occupations amongst these two sectors consistent with hospitality workers and checkout operators having some of the lowest RRs. The exception was retail/hospitality managers.

\section{Retirement rates (RRs) for Occupations Ranked by Highest RRs for 2006-13}

The retirement rates (RRs) are ranked according to average rates over the 2006-13 period with the top 30 reported in Table 11. The RR for this period equalled or exceeded 2.0 for six occupational groups covering a range of skill levels. Personal Assistants and Secretaries (Semi-skilled occupation) had the highest rate (2.4 per cent) followed by Textile, Clothing and Footwear Trades Workers (Skilled occupation) which is also projected to rise much faster compared to others over the 2013-20 period.

Real Estate Sales Agents, Tertiary Education Teachers and Farmers and Farm Managers with either a high per cent of workers in the retirement age and/or a high median age are estimated to be having RRs of around 2.0 per cent. By comparison, Automobile, Bus and Rail Drivers with the highest

\section{Table 11: Occupations top 30 Retirement rates for 2006-13 and Forecast rates for 2013-20}

proportion of workers in retirement age (65 years and over) do not have a correspondingly high level of RR as workers in this occupational group are able to continue to work past this age.

The remaining occupational groups in the top 30 are in a range of sectors including Education (242, 249, 134 and 241), Hospitality and Retail (141 and 142), a number of Trades occupations (393, 392, 331, 323, 394 and 332) covering many industries, several service and support workers in the Semiskilled group (521, 531, 532, 552, 423 and 542) along with numerous Elementary occupations (711, $733,712,731,832$ and 831 ) including machine operators, drivers, assemblers and process workers.

\section{Conclusions}

The ageing of the workforce in New Zealand is an important determinant of participation and retirement decisions of older retirement age (65 years and older) and slightly younger workers. Even if the ageing of the workforce in New Zealand is not as high as it is in Japan or even the UK and the participation rates of those who are 65 years and over is projected to rise from about 20 per cent (in 2011) to 30 per cent (in 2026), growth in the labour supply is expected to decline by the end of this decade.

In order to understand the specific impacts on the labour market, the extent of ageing and the estimated retirement rates are usefully studied by occupational groups and broad skill groups. The measures of ageing by occupational groups assessed in this paper using the median age and more importantly the proportion of workers in the retirement age (65 years and over) suggest that the links are not straight forward or always transparent. Some other factors related to the nature of the occupations (Professional or those in Trades requiring greater physical exertion) and personal circumstances (both health and financial ability to retire) play a key role. 
In general, those industries and sectors with occupations having a higher median age and/or larger proportion of workers in the retirement age also exhibit higher average retirement rates, both estimated (for recent periods) and projected (for the next 5-7 years), with some minor exceptions. The Education sector appears to include occupations which are on average older for example than those in the Health sector and have higher estimated retirement rates.

In comparison, the occupations in Engineering related activities and those in the Construction sector on average appear to have a somewhat lower proportion of workers in the retirement age and lower retirement rates than those in Education, but certain selected occupations have similar estimated retirement rates.

\section{References}

Access Economics, (2012), "Modelling of future skills demand: the implications for skills planning in NSW.", Comparing the implications of three alternate migration scenarios for Skills Australia.

Alpass, F. and Mortimar, R., (2007). "Ageing Workforces and Ageing Occupations: A Discussion Paper.", A report to the Department of Labour, Massey University, Palmerston North, 2007.

Beach, C. M., (2008). “Canada's Aging Workforce: Participation, Productivity, and Living Standards.”, A Festschrift in Honour of David Dodge. November, Bank of Canada, p.197-218.

Carriere, Y. and Galarneau, D., (2011). “Delayed Retirement: A new trend?", Perspectives on labour and Income, Vol. 23, no. 4. Winter. Statistics Canada, cat no. 75-001-X.

Denton, F. T. and Spencer B. G., (2008). "What is Retirement? A Review and Assessment of Alternative Concept and Measures.", SEDAP Research Paper No. 231, Social and Economic Dimensions of an Aging Population, Hamilton, McMaster Uni, 39 p.

Gower, D., (1997). "Measuring the age of retirement.", Perspectives on labour and Income, Vol. 9, no. 2. Summer. Statistics Canada, catalogue no. 75-001-X. p. 11-17.

Guest, R., (2013), "Comparison of the New Zealand and Australian Retirement Income Systems.", background paper for the 2013 review of retirement income policy by the Commission for Financial Literacy and Retirement Income, Griffith University.

Hunnard, R., (2005), "The effect of New Zealand Superannuation eligibility age on the labour force participation of older people.", New Zealand Treasury Working Paper 05/09, November 2005

National Institute of Aging, (2014), "Work and Retirement.", Chapter 2 in Growing Older in America: The Health and Retirement Study, National Institute of Health, USA.

PostNote, (2011). "An Ageing Workforces.", Parliamentary Office of Sciences \& Technology, UK Houses of Parliament, Number 391, October 2011

Riffkin, R., (2014), “Average U.S. Retirement Age Rises to 62.”, in Economy, Gallup, April 28, 2014

Shah, C. \& Burke, G., (2001), "Occupational replacement demand in Australia. International Journal of Manpower, 22(7), 648-663. 